33. Березина Н.А., Афанасьева Н.Б. Экология растений. М.: Академия, 2009. 400 с.

34. Богданова Я.А. Предварительные данные по изучению липовых лесов Красносамарского лесного массива и Бузулукского бора // Тезисы докладов III (XI) Международной Ботанической конференции молодых учёных в Санкт-Петербурге. СПб.: ЛЭТИ, 2015. C. 134.

\title{
ON THE IDENTIFICATION OF ECOLOGICAL OPTIMUM OF BRYOPHYTES
}

(C) 2016

Y.A. Bogdanova, postgraduate student of the Chair of Ecology, Botany and Nature Protection

E.S. Korchikov, candidate of biological sciences,

associate professor of the Chair of Ecology, Botany and Nature Protection

N.V. Prokhorova, doctor of biological sciences, professor of the Chair of Ecology, Botany and Nature Protection

Samara State Aerospace University, Samara (Russia)

Abstract. This article describes a method for detecting synecological optima of bryophytes and the possibility of their use in phytoindication of ecological conditions of the biotope. Bryophytes may take a significant part in plant communities, they have the ability to accumulate heavy metals, they can be used to determine the degree of the anthropogenic load and of the formation of forest communities. All this makes them excellent bioindicators, which can give an almost complete description of the plant community. But to do this it is necessary to know the environmental optima of mosses. At the moment, there are sparse data on the environmental characteristics of the bryophytes, it is not always clear how these characteristics were obtained. Currently, there are several ways to determine the environmental optima of the bryophytes based on the occurrence data and the projective cover of mosses. These methods use L.G. Ramenskiy's scales for vascular plants, these scales are extrapolated to bryophytes. Using our experience in defining synecological optima of lichen, we offer a graphical method for identifying ecological optimum of the bryophytes in which A.L. Bellegard's ecomorph scales are applied in the modification of N.M. Matveev (for the forest-steppe zone) and D.N. Tsyganov (for the coniferousdeciduous forest subzone). The essence of this method is the plotting of a graph of the quantitative characteristics of a particular moss depending on the environmental factors. For this you need to carry out phytoindication of the biotope community by using vascular plants and determine the average cover of moss or vitality of this moss.

Keywords: phytoindication, bryoindication, synecological optimum, bryophytes, environmental characteristics of mosses, ecobiomorphs, Pseudoleskeella nervosa (Brid.) Nyh, vitality of bryophytes.

УДК $581.9(470.315)$

\section{ФЛОРА ПОСЕЛКА ЛУХ ИВАНОВСКОЙ ОБЛАСТИ}

(C) 2016

E.А. Борисова, доктор биологических наук, заведующий кафедрой общей биологии и физиологии Ивановский государственный университет, Иваново (Россия)

Аннотащия. В статье приводятся данные изучения флоры одного из древних поселений Ивановской области поселка Лух. В результате исследований, проведенных в период 2008-2014 гг., в современной флоре поселка и его ближайших окрестностей выявлено 402 вида сосудистых растений, относящихся к 3 отделам, 4 классам, 78 семействам и 255 родам. Ведущими семействами флоры являются Compositae - 53 вида (13,2\%), Rosaceae - 39 видов (9,7\%), Poaceae - 27 вида (6,7\%), Fabaceae - 23 вида (5,7\%), Cruciferae - 18 видов (4,2\%). Основу биоморфологической структуры флоры составляют многолетние травянистые растения (233 вида, 57,9\%), на долю древесных приходится 60 видов (14,9\%), среди которых 23 вида деревьев, 33 вида кустарников. Проведение географического анализа позволило установить преобладание видов местной флоры. Аборигенный компонент флоры поселка составляют 247 видов (61,6\%), адвентивный компонент представлен 153 видами (38,4\%). Индекс адвентивизации, характеризующий степень антропогенной трансформации флоры, составляет 0,38 , что типично для малых городов Верхневолжского региона. Кратко охарактеризованы 2 вида (Gerntiana pneumonanthe, Populus nigra), включенные в региональную Красную книгу, редкие виды флоры области (Thelypteris palustris, Dactulorhiza fuchii, Platanthera bifolia, Convallaria majalis, Carex pilosa, Trollius earopaeus, Daphne mezerum и др.), а также некоторые редкие адвентивные виды (Atriplex patens, Symphytum $\times$ uplandicum, Hesperis matronalis, Veronica persica, Zizania latifolia).

Ключевые слова: флора сосудистых растений, антропогенная трансформация флоры, индекс адвентивизации, редкие виды растений, Красная книга, адвентивные виды, инвазионные виды, структура флоры, флора сельских населенных пунктов, флора древних поселений, Ивановская область, поселок Лух.

Введение. Закономерности формирования флоры сельских поселений в настоящее время становится приоритетным направлением флористических исследований, как в нашей стране $[1,2,3,4]$, так и за рубежом $[5,6,7]$. Особенно актуальны изучение флоры древних поселений, известных с доисторических времён.

Ивановская область расположена в центральной части Европейской России, в междуречье Волги и Клязь- мы. Область отличается высоким уровнем урбанизации, на ее территории расположено 17 городов и более 50 крупных поселков и сел. Поэтому изучения флоры населенных пунктов, особенностей ее формирования и динамики особенно актуальны.

Изучение флоры различных населенных пунктов Ивановской области проводится планомерно, начиная с 1990-х гг., к настоящему времени хорошо изучены 
флоры посёлков Богородское [8], Демидово [9], Луговое [10], сёл Ильинское, Мытищи, д. Быково и др.

Поселок Лух расположен в центральной части Ивановской области, в 94 км восточнее г. Иваново, в долине правого берега р. Лух (левый приток Клязьмы). Лух - одно из древних поселений Ивановской области, дата основания которого точно не установлена. Первые упоминания о нём относятся еще к началу XIII в., в 1429 г., в Софийской летописи он упоминается как древнерусский город-крепость [11], в 1552 г. Лух известен как пограничная крепость Владимиро-Суздальского княжества, управляемая воеводой. С 1708 г. Лух становится уездным городом Московской, позднее в 1778 г. Костромской губерний. В 1800 г. город был почти дотла уничтожен пожарами и отстраивался заново [12], с 1918 г. Лух - город образованной ИвановоВознесенской губернии. В 1925 г. Лух, город с 500летней историей был преобразован в село Кинешемского уезда, позднее в 1959 г. - в поселок городского типа.

В настоящее время Лух - крупный поселок, центр муниципального Лухского района. Согласно данным областного статистического управления население поселка составляет 2,9 тысяч человек, площадь поселка $2,98 \mathrm{kм}^{2}$. На его территории действуют более 5 крупных агропромышленных предприятий, развито огородничество. В планировке поселка сохранились черты древнерусских городов, имеется центральная торговая площадь, от которой веером расходятся улицы, соединенные в кольцо. В застройке поселка преобладают индивидуальные жилые дома с участками.

В центре поселка на правом берегу р. Лух расположен парк, который имеет историческое и природное значение. На территории парка сохранились земляные валы древней Лухской крепости, которые являются памятником архитектуры федерального значения [13]. Парк имеет статус ООПТ регионального значения (Peшение Исполкома областного Совета № 164 от 22.02.1965). В начале 2000-х гг. был разработан проект по восстановлению деревянной крепости на территории парка для развития туризма, но не был доведен до конца. В результате строительства крепости в парке были вырублены многие старовозрастные деревья. В 2012-2013 гг. проведены работы по завершению строительства крепости и благоустройству парка, высажены декоративные деревья и кустарники. Посёлок Лух входит в число наиболее благоприятных в экологическом отношении регионов Европейской России, обладает богатейшими рекреационными возможностями, его окрестности очень живописны.

Материалы и методика. В течение полевых сезонов 2008-2009 гг. были проведены исследования флоры на территории поселка и в его ближайших окрестностях. Флористически были изучены различные типы природных сообществ (разные типы лугов по берегам p. Лух, участки сосновых сосново-елово-березовых и березовых лесов на окраинах поселка, заболоченные участки), а также различные антропогенные экотопы (обочины дорог, полигон отходов, пустыри, огороды и др.). Был изучен видовой состав различных типов озеленения посёлка и старый усадебный парк «Малиново». Активное участие в проведении исследований принимала студентка биологического отделения ИвГУ, Д. Вареева, за что автор выражает ей сердечную признательность. В 2014 г. в рамках работы по ведению Красной книги Ивановской области был обследован парк в посёлке, луга по берегу р. Лух и леса на северной окраине поселка. В 2014 г. в исследованиях участвовали магистры кафедры общей биологии и физиологии ИвГУ М. Мишагина и А. Курганов. Гербарные образцы видов растений, собранных в пос. Лух, хранятся в гербарии Ивановского государственного университета (IVGU), имеющиеся дубликаты редких видов переданы в гербарий им. Д.П. Сырейщикова (MW).

Результаты и их обсуждение. В результате исследований в современной флоре поселка и его ближайших окрестностях было отмечено 402 вида сосудистых растений, относящихся к 3 отделам, 5 классам, 78 семействам и 255 родам. Среди них василёк горный (Centaurea montana L.) впервые приводятся для флоры Ивановской области [14], 2 вида (Gerntiana pneumonanthe L., Populus nigra L.) включены в Красную книгу Ивановской области [15], 12 видов относятся к числу редких, требующих специальной охраны [16].

Основу систематической структуры флоры составляют представители отдела покрытосеменные - Magnoliophyta (388 видов), отдел Eguisetophyta представлен 6 видами, отдел Gymnospermae - 5 видами, отдел Polypodiophyta - 4 видами. Представители отдела Lycopodiophyta отсутствуют. Среди покрытосеменных (Magnoliophyta) преобладают растения класса двудольные (315 видов; 78,4\%), на долю однодольных приходится 72 вида (17,9\%). Среди класса однодольных ( Liliopsida, Monocotyledones), богато представлены семейства Poасеае и Cyperaceae, что связано с сохранившимися различными типами лугов по берегу р. Лух. Спектр 10 ведущих семейств современной флоры поселка представлен в таблице 1.

Таблица 1 - Спектр ведущих семейств флоры пос. Лух

\begin{tabular}{|r|l|c|c|c|c|}
\hline$№$ & $\begin{array}{c}\text { Название } \\
\text { семейства }\end{array}$ & $\begin{array}{c}\text { Число } \\
\text { видов }\end{array}$ & $\begin{array}{c}\text { об от } \\
\text { оисго } \\
\text { видов }\end{array}$ & $\begin{array}{c}\text { Число от } \\
\text { родов }\end{array}$ & $\begin{array}{c}\text { общего } \\
\text { числа } \\
\text { видов }\end{array}$ \\
\hline 1 & Compositae & 53 & 13,2 & 41 & 16,1 \\
\hline 2 & Rosaceae & 39 & 9,7 & 21 & 8,2 \\
\hline 3 & Poaceae & 27 & 6,7 & 19 & 7,5 \\
\hline 4 & Fabaceae & 23 & 5,7 & 10 & 3,9 \\
\hline 5 & Cruciferae & 18 & 4,2 & 17 & 6,6 \\
\hline 6 & Labiatae & 13 & 3,2 & 10 & 3,9 \\
\hline 7 & Umbelliferae & 13 & 3,2 & 12 & 4,7 \\
\hline 8 & Salicaceae & 12 & 2,9 & 2 & 0,1 \\
\hline 9 & Cyperaceae & 12 & 2,9 & 3 & 1,1 \\
\hline 10 & Caryophyllaceae & 12 & 2,9 & 9 & 3,5 \\
\hline \multicolumn{2}{|c|}{ Bcero } & 221 & 51,7 & 144 & 56,5 \\
\hline
\end{tabular}

В целом систематическая структура флоры пос. Лух характеризуется низкой видовой насыщенностью семейств. На долю 10 ведущих семейств флоры приходится более половины всего видового состава $(51,7 \%$, 255 видов); на долю первых трёх - 29,6\% (119 видов), на долю первых пяти - 39,6\% (159 видов).

Среди семейств, представленных только 1 видом, отметим ароидные (Araceae), буковые (Fagaceae), кирказоновые (Aristolochiaceae), рогозовые (Typhaceae), частуховые (Alismataceae), липовые (Tiliaceae), валериановые (Valerianaceae) и некоторые другие.

К крупным родам современной флоры поселка относятся следующие: Carex -8 видов, Salex и Potentilla - по 7 видов, Equisetum, Rumex, Veronica и Ranunculus по 6 видов, Trifolium, Juncus, Vicia - по 5 видов. 
Биоморфологический анализ флоры пос. Лух был поведен по системе И.Г. Серебрякова [17] с небольшими изменениями. Особенности биоморфологической структуры флоры представлены в таблице 2 .

Таблица 2 - Биоморфологическая структура флоры пос. Лух

\begin{tabular}{|l|c|c|}
\hline \multicolumn{1}{|c|}{$\begin{array}{c}\text { Название } \\
\text { жизненнй формы }\end{array}$} & $\begin{array}{c}\text { Число } \\
\text { видов }\end{array}$ & $\begin{array}{c}\text { \% от общего } \\
\text { числа видов }\end{array}$ \\
\hline Деревья & 23 & 5,7 \\
\hline Кустарники & 33 & 8,2 \\
\hline Кустарнички & 2 & 0,5 \\
\hline Деревянистая лиана & 2 & 0,5 \\
\hline $\begin{array}{l}\text { Многолетние } \\
\text { травянистые растения }\end{array}$ & 233 & 57,9 \\
\hline Двулетние & 18 & 4,5 \\
\hline Однолетние & 86 & 21,5 \\
\hline Одно- и двулетние & 5 & 1,2 \\
\hline
\end{tabular}

В биоморфологической структуре флоры пос. Лух преобладают многолетние травянистые растения, представленные 233 видами, что составляет более половины всего видового состава. Малолетние травянистые растения представлены 109 видами (27,3\%), среди них преобладают однолетние. Древесные растения представлены 60 видами (14,9\%), среди которых 23 вида деревьев и 33 вида кустарников, к кустарничкам отнесено 2 вида (Vaccinium myrtillus, $V$. vitis-idaea).

Проведение географического анализа позволило установить значительное преобладание видов местной флоры. Аборигенный компонент флоры поселка составляют 247 видов (61,6\%). Его основу формируют лесные, луговые, лугово-опушечные, водные и прибрежно-водные виды. Благодаря тому, что на территории поселка сохранились различные природные сообщества в составе флоры много редких растений флоры Ивановской области. В сосновых и сосново-елово-березовых на северной окраине поселка отмечены группы Thelypteris palustris, Juniperus communis, Dactulorhiza fuchii, Platanthera bifolia, крупные заросли Convallaria majalis, Carex pilosa. В березово-еловых лесах на восточной окраине поселка встречаются группы Trollius earopaeus, единичные экземпляры Daphne mezerum.

В составе пойменных лугов по р. Лух присутствуют группы Dactulorhiza incarnata, Dianthus superbus, реже встречаются Centaurium erythrea, Campanula percicifolia. По берегам р. Лух отмечены крупные заросли Iris pseudacorus, Ranuncalua lingua, единичные экземпляры Dactulorhiza incarnata. В заводях р. Лух часто встречаются группы Nymphaea candida. Bсе перечисленные виды включены в дополнительный список региональной Красной книги и нуждаются в постоянном контроле состояния популяций. Среди редких видов в пределах поселка отмечены крупные устойчивые популяции, Dactulorhiza fuchii, Convallaria majalis, Iris pseudacorus и Nymphaea candida.

Адвентивный компонент флоры поселка представлен 153 видами, что составляет 38,4\% от общего числа видов. Индекс адвентивизации, характеризующий степень антропогенной трансформации флоры, составляет 0,38 , что типично для малых городов и крупных поселков Верхневолжского региона [18].

Среди наиболее интересных заносных видов отметим Atriplex patens, Symphytum $\times$ uplandicum, Hesperis matronalis, Veronica persica, Zizania latifolia. Atriplex patens - редкий заносный, галофильный вид, который впервые был обнаружен в Ивановской области в 1997 г. [19] и к настоящему времени известен всего из 3 пунктов области. Группа вегетативных особей Zizania latifolia найдена по берегу небольшой заводи р. Лух на юге поселка. Данный вид известен в области только по берегам Волги в окрестностях Плеса и р. Решемки в с. Решма. Рассеянные группы Veronica persica были обнаружены на пустыре у фермы и вдоль дороги на юговосточной окраине поселка. Заросли Symphytum $\times$ uplandicum найдены на сбитых лугах по р. Лух на юге поселка и у д. Бабино. Группа вегетативных и цветущих экземпляров Silybum marianum была найдена на склоне p. Лух (14 июля 2009 г. - IVGU). Этот вид стал выращиваться в Ивановской области как декоративное и лекарственное растений только в начале 2000-х г., в 2006 г. отмечены первые случаи дичания этого вида [20].

Среди сорно-рудеральных растений в поселке обычны Echinochloa crusgalli, Chenopodium album, Berteroa incana, Sisymbrium officinale, Thlaspi arvense, Sinapis arvensis, Echium vulgare, Chamomilla suaveolens, Cirsium arvense, Erigeron canadensis, Matricaria perforata, Senecio vulgaris, Sonchus arvensis.

На территории поселка встречаются и многие адвентивные растения, например, Bryonia alba, Centaurea cyanus, Sinapis alba, Raphanus raphanistrum, Lycopsis arvensis, Urtica urens, которые в последние десятилетия значительно сократили области распространения в Верхневолжском регионе [21].

Среди адвентивных видов флоры поселка особо выделяются инвазионные, которые успешно натурализовались и отмечены в различных типах нарушенных и природных сообществах. К инвазионным и потенциально-инвазионным относятся 16 видов, которые также являются инвазионными растениями Верхневолжского региона [22, 23]. Среди них отметим Amelanchier spicata, Aronia melanocarpa, Sambucus racemosa, Cerasus vulgaris, Grossularia reclinata, обычно встречающиеся в составе подлеска лесов на окраинах поселка, группы Aquilegia vulgaris - на опушках лесов. Небольшие заросли североамериканских растений Juncus tenuis, Oenothera rubricaulis, Solodago canadensis обычны вдоль дорог, в 2014 г. отмечено их присутствие на олуговелых склонах берегов р. Лух в центральной части поселка. На лугах по берегам р. Лух крупные заросли формирует Epilobium adenocaulon, Bunias orientalis, реже встречается Galeopsis bifidum. В воде реки и прудов в поселке часто отмечается Elodea canadensis.

Вызывает тревогу распространение по территории поселка Heracleum sosnowskyi, Festuca arundinaceae, Xanthium albinum, Impatiens parviflora, которые встречаются большими группами.

Наибольшее число адвентивных видов сконцентрировано на полигоне отходов, который расположен на южной окраине поселка. Здесь отмечены многочисленные дичающие интродуценты (например, Populus balsamifera, Papaver somniferum, Faba bona, Anethum graveolens, Coriandrum sativum, Mentha longifolia, Physalis alkehengi, Lycopersicon esculentum, Cusumis sativus, Lonicera tatarica, Ageratum houstonianum, Cosmos bipinnatus, Helianthus tuberosus, Rudbeckia laciniata, Tagetes patula, Zinnia elegans и др.) и сорно-рудеральные виды (Amaranthus retroflexus, Atriplex patula, A. nitens, Chenopodium glaucum, Chenopodium polyspermum, Spergula arvensis, Fumaria officinalis, Vicia angustifolia и др.).

Отмеченные виды по территории поселка распространены неравномерно. С использованием представ- 
ления об активности видов в понимании Б.А. Юрцева и разработанной им 5-балльной шкалы $[24,25]$ была проведена оценка активности видов, слагающих флору поселка. Распределение видов по степени активности представлено в табл. 3 .

Таблица 3 - Распределение видов по степени активности

\begin{tabular}{|c|c|c|c|c|}
\hline $\begin{array}{c}\text { Баллы } \\
\text { актив- } \\
\text { ности }\end{array}$ & $\begin{array}{c}\text { Число } \\
\text { местных } \\
\text { видов }\end{array}$ & $\begin{array}{c}\text { \% от об- } \\
\text { щего чис- }\end{array}$ & $\begin{array}{c}\text { Число } \\
\text { адвентив- } \\
\text { ных видов }\end{array}$ & $\begin{array}{c}\text { \% от об- } \\
\text { щего чис- } \\
\text { ладов }\end{array}$ \\
\hline 1 & 9 & 2,24 & 21 & 5,22 \\
\hline 2 & 90 & 22,38 & 78 & 19,4 \\
\hline 3 & 92 & 22,9 & 33 & 8,21 \\
\hline 4 & 48 & 11,9 & 17 & 4,23 \\
\hline 5 & 10 & 2,49 & 4 & 0,19 \\
\hline Всего & 249 & 61,91 & 153 & 37,25 \\
\hline
\end{tabular}

Как видно из таблицы 3, во флоре пос. Лух и в его ближайших окрестностях явно преобладают малоактивные виды (активность 1 и 2 балла), вместе они составляют почти половину всего видового состава (49,3\%; 198 видов). Среднеактивные виды тоже многочисленны, их насчитывается 125 видов (31,4\%). Активные виды, которые широко распространены по территории поселка, образуя заросли, представлены 79 видами. Среди активных, массовых видов отметим обычные луговые растения Agrostis alba, A. tenuis, Calamagrostis epigeios, Deschampsia caespitosa Elytrigia repens Phleum pretense, Poa palustris, Carex chirta, Ranunculus acris, Potentilla erecta, Medicago lupulina, Trifolium repens, Pimpinella saxifraga, Achillea millefolium, Centaurea pseudophrygia и др.

Поселок Лух хорошо озеленен, на его территории действует парк, на торговой площади у памятников и храмов разбиты большие цветники, очень декоративны аллеи из лиственницы сибирской, ведущей к памятнику Н.Н. Бенардосу и ели колючей (Picea pungens, forma glauca) у средней школы. Жители посёлка активно благоустраивают прилегающие к домам территории, высаживая различные виды декоративных растений, формируют разнообразные цветники. Вдоль дорог посажены различные виды тополей (Populus $\times$ sibirica, P. balsamifera, реже $P$. alba), липа сердцелистная, рябина обыкновенная, клен американский, ясень пенсильванский. Среди кустарников обычны Crataegus altaica, Caragana arborescens, Rosa rugosa, Prunus spinosa, Spiraea chamaedryfolia и другие. Редко встречаются такие декоративные кустарники как Syringa vulgaris, Sorbaria sorbifiolia, Rosa majalis, $R$. spinosissima, Spiraea japonica. Очень редко у домов отмечены высокие экземпляры Juniperus communis и лиана Parthenocissus inserta.

В 3,5 км восточнее пос. Лух в живописном месте на берегу реки расположена старинная помещичья усадьба «Малиново». Усадебный дом уже давно полностью разрушен. В заброшенном парке сохранилось много старовозрастных деревьев Pinus sylvestris, Picea abies, Ulmus laevis, Quercus robur. Встречаются отдельные деревья ясеня высокого - Fraxinus excelsior и Malus domestica. В планировке парка выделяются рядовые посадки из Betula pendula и небольшой пруд овальной формы. Из декоративных кустарников здесь сохранились группы высоких растений Caragana arborescens, кусты Ribes nigrum, Lonicera tatarica. Среди травяни- стых растений встречаются заросли Fragaria moschata, Centaurea montana, которые специально выращивались в усадебных парках начала XIX в. В парке встречаются группы орхидных растений (Dactulorhiza fuchii, Platanthera bifolia), в массе отмечены Convallaria majalis, Trollius earopaeus. В небольшом мелководном пруду парка растут обычные водные растения (Hydrocharis morsus-ranae, Eleocharis polustris, Calla palustris, Spirodela polyrhiza, Lemna trisulca и др.). По берегу пруда встречаются старовозрастные деревья с развесистыми кронами Salix fragilis.

В целом, во флоре бывшего усадебного парка «Малиново» отмечено более 60 видов сосудистых растений, среди которых 7 относятся к редким для флоры Ивановской области. Деревья и сеянцы редкого вида декоративных лиственных пород ясеня высокого, находящегося в парке в хорошем состоянии, можно рекомендовать для использования в озеленении поселка.

Заключение. Таким образом, флора пос. Лух богата и разнообразна, к 2015 г. в ее составе насчитывается 402 вида сосудистых растений. По всем основным показателям структуры флора поселка типична для бореальных флор и сходна со флорами малых городов Ивановской области. Присутствие в составе флоры редких видов растений, в том числе 2-х видов региональной Красной книги, обусловлено наличием природных сообществ на окраинах поселка и по берегу р. Лух.

Флористические исследования на территории поселка следует продолжить, за состоянием популяций редких видов нужно проводить мониторинговые наблюдения. Также необходим контроль за распространением по территории поселка адвентивных, особенно инвазионных растений.

\section{СПИСОК ЛИТЕРАТУРЫ:}

1. Говоров Е.В. Особенности флоры населенных пунктов сельского типа лесостепной зоны Башкирского Предуралья // Итоги биологических исследований. Уфа, 2001. Вып. 7. С. 162-165.

2. Раков Н.С. О флоре и растительности с. Архангельское (левобережье Ульяновской области) // Фиторазнообразие Восточной Европы. 2006. № 1. С. 47-87.

3. Кравченко А.В., Тимофеева В.В., Фадеева М.А. О флоре рудеральных ландшафтов Прибеломорской Карелии // Тр. Карельского науч. Центра. Вып. 12, 2008. C. $74-92$.

4. Голюшева А.Н. О флоре поселка городского типа Чердаклы (Ульяновское Заволжье) // Экология и география растений и сообществ Среднего Поволжья /под ред. С.А. Сенатора, С.В. Саксонова, Г.С. Розенберга. Тольятти: Касандра, 2011. С. 157-161.

5. Pysek P. A factors affecting the diversity of flora and vegetation in central Europaean settlements // Vegetatio. 1993. V. 106. P. 89-100.

6. Kim Y.-M., Zerbe S., Kovarik. I. Human impact on flora and habitats in Korean rural settlements // Preslia. 2002. V. 74. P. 407-419.

7. Krigas N., Kokkini S. A suvey of the alien vascular flora of the urban and suburban area of Thessaloniki, $\mathrm{N}$ Greece // Willdenowia. 2004. V. 34. P. 81-99.

8. Борисова Е.А. Динамика синантропной флоры поселка Богородское (Ивановская область, Ивановский р-н.) //Краеведческие записки. Вып. 6-7. Иваново: Издво ИвГЭУ, 2000. С. 191-194.

9. Флора окрестностей поселка Демидово Пестяковского района Ивановской области // Современные про- 
блемы биологии, химии, экологи и экологического образования: Регион. сб. науч. тр. Ярославль: Изд-во Яросл. гос. ун-та, 2001. С. 133-136.

10. Борисова Е.А. Луговое - один из интересных природно-флористических комплексов в окрестностях г. Кинешма // Историко-культурный и природный потенциал Кинешемского края. Кинешма, 2006. С. 161-163.

11. По земле Ивановской: Историко-краеведческие очерки. Ярославль: Верх.-Волж. кн. изд-во, 1983. 319 с.

12. Попович А.А. История изучения городища в поселке Лух // Краеведческте записки. Вып. IX, Иваново: Иван. гос. ун-т, 2009. С. 25-28.

13. Ерофеева Е.Н. Археологические памятники Ивановской области. Ярославль: Верхне-волжск. кн. издво, 1965.

14. Борисова Е.А. Новые адвентивные виды растений в Ивановской и Владимирской областях // Бюл. МОИП, Отд. Биол. 2009. Т. 114, вып. 6. С. 61-62.

15. Красная книга Ивановской области. Т. 2: растения и грибы / Е.А. Борисова, М.А. Голубева, М.П. Шилов и др. Иваново: ПресСто, 2010. 192 с.

16. Борисова Е.А. Интересные флористические находки в поселке Лух и его окрестностях // Борисовский сборник. Вып. 3. / под ред. В.В. Возилова. Иваново: Изд. дом Референт, 2012. С. 190-193.

17. Серебряков И.Г. Экологическая морфология растений: жизненные формы покрытосеменных и хвойных. М.: Высш. школа, 1962. 378 с.
18. Борисова Е.А. Адвентивная флора Ивановской области. Иваново: Иван. гос. ун-т, 2007. 188 с.

19. Борисова Е.А., Голубева М.А. Сведения о новых заносных и дичающих видах в Ивановской, Костромской областях // Флористические исследования в Центральной России на рубеже веков: Материалы науч. совещ. М.: Бот. сад МГУ, 2001. С. 28-31.

20. Борисова Е.А.,, Сенюшкина И.В. Флористические находки в Ивановской области // Бюл. МОИП. Отд. биол. 2007. Т. 112, вып. 6. С. 41-42.

21. Борисова Е.А. Формирование адвентивного компонента флоры Верхневолжского региона // Биоразнообразие: проблемы изучения и сохранения: Матер. междунар. науч. конф., посв. 95-летию каф. ботаники Тверского гос. ун-та. Тверь: ТвГУ, 2012. С. 339-342.

22. Борисова Е.А. Инвазионные виды во флоре Верхневолжья // Актуальные вопросы изучения флоры Верхневолжья: Мат. регион. науч. конф. (Иваново, 12 13 окт. 2007 г.). Иваново: Иван. гос. ун-т, 2007. С. 14-20.

23. Борисова Е.А Особенности распространения инвазионных видов растений по территории Верхневолжского региона // Российский журн. биологических инвазий. 2010, № 4. С. 2-9.

24. Юрцев Б.А. Флора Сунтар-Хаята. Л.: Наука, 1968. $236 \mathrm{c}$.

25. Юрцев Б.А. Флора как природная система // Бюл. МОИП. Отд. биол. 1982. Т. 87, вып. 4. С. 3-32.

\section{FLORA OF THE SETTLEMENT LUKH OF IVANOVO REGION}

(C) 2016

E.A. Borisova, doctor of biological sciences, head of the Chair of General Biology and Physiology Ivanovo State University, Ivanovo (Russia)

Abstract. In the article the floristic data of Lukh, one of the ancient Ivanovo region settlements, are given. The present Lukh settlement flora consists of 402 vascular plant species from 4 classes, 76 families and 255 genera. Compositae - 53 species (13,2\%), Rosaceae - 39 species (9,7\%), Poaceae - 27 species (6,9\%), Fabaceae - 23 species $(5,7 \%)$, Cruciferae -18 species $(4,2 \%)$ are leading families of the flora. The basis of biomorphological structure of the Luch flora is made up by the perennial grass plants (233 species; 57,9\%), arboreous plants include 60 species (14,9\%), among which 23 species are trees, 33 species are shrubs. Geographical analysis ascertained prevalence of native species. The native component of Lukh flora comprises 247 species $(61,6 \%)$, the alien component -153 species $(38,4 \%)$. The adventivity index is 0,38 which is typical for the small towns and large settlements of the Upper Volga region. 2 rare species (Gerntiana pneumonanthe, Populus nigra) included in the regional red data book, some native (Thelypteris palustris, Juniperus communis, Dactulorhiza fuchii, Platanthera bifolia, Convallaria majalis, Carex pilosa, Trollius earopaeus, Daphne mezerum) and alien (Atriplex patens, Symphytum x uplandicum, Hesperis matronalis, Veronica persica, Zizania latifolia) rare plant species are briefly characterized.

Keywords: flora of the vascular plant species, anthropogenic transformation of the flora, human activity index, rare plant species, Red data book, alien plant species, invasion plant species, structure of the flora, flora of rural settlements, floristic data of ancient settlement, Ivanovo region, Lukh settlement.

УДК 574.5 (285.3); $504(1-21)$

\section{РАКООБРАЗНЫЕ И КОЛОВРАТКИ ПРУДА ВОЗЛЕ ТОРГОВОГО ЦЕНТРА «ПИРАМИДА» (Г. САМАРА) В 2013 Г.}

(C) 2016

Ю.Л. Герасимов, кандидат биологических наук, заведующий кафедрой зоологии, генетики и общей экологии Самарский государственный аэрокосмический университет имени академика С.П. Королева, Самара (Россия)

А.В. Шабанова, кандидат химических наук, доцент кафедры природоохранного и гидротехнического строительства Самарский государственный архитектурно-строительный университет, Самара (Россия)

Аннотащия. Изучены видовой состав и численность популяций ракообразных и коловраток городского пруда после проведения мелиоративных работ. В пруду выявлено 30 видов коловраток (до мелиорации отмечалось 52 вида). По численности сохранили доминирование семейства Brachionidae, Synchaetidae и Asplanchnidae. Ракооб- 